\title{
Article
}

\section{Intimate partner violence: Are the risk factors similar for men and women, and similar to other types of offending?}

Thornton, Abigail, Graham-Kevan, Nicola and Archer, John

Available at http://clok.uclan.ac.uk/13404/

Thornton, Abigail ORCID: 0000-0002-6619-2864, Graham-Kevan, Nicola ORCID: 0000-0003-0621-3093 and Archer, John ORCID: 0000-0003-0483-1576 (2015) Intimate partner violence: Are the risk factors similar for men and women, and similar to other types of offending? Aggression behavior, 42 (4). pp. 404-412. ISSN 0096-140X

It is advisable to refer to the publisher's version if you intend to cite from the work. http://dx.doi.org/10.1002/ab.21635

For more information about UCLan's research in this area go to http://www.uclan.ac.uk/researchgroups/ and search for <name of research Group>.

For information about Research generally at UCLan please go to http://www.uclan.ac.uk/research/

All outputs in CLoK are protected by Intellectual Property Rights law, including Copyright law. Copyright, IPR and Moral Rights for the works on this site are retained by the individual authors and/or other copyright owners. Terms and conditions for use of this material are defined in the policies page.

\section{CLoK}

Central Lancashire online Knowledge www.clok.uclan.ac.uk

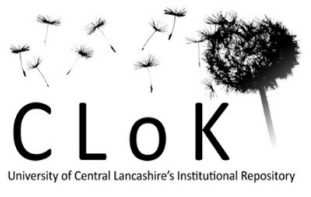




\title{
Intimate Partner Violence: Are the Risk Factors Similar for Men and Women, and Similar to Other Types of Offending?
}

\author{
Abigail J.V. Thornton, Nicola Graham-Kevan, and John Archer* \\ School of Psychology, University of Central Lancashire, Preston, United Kingdom \\ : : : : : : : : : : : : : : : : : : : : : : : : : : : : : : : : : :
}

We studied intimate partner violence (IPV) within a framework of other violent and nonviolent offending, to explore whether the risk factors for offending were similar across the different offense categories, and also for men and women. A comprehensive measure of offending behavior was administered to 184 men and 171 women, together with measures of anger, self-control, and psychopathic traits. The measure, the nonviolent and violent offending behavior scale (NVOBS), assesses IPV, general violence, and nonviolent offending behavior. Men perpetrated higher levels of general violence and nonviolent offenses than women, whereas women perpetrated significantly more IPV than men. Regression analyses showed that the predictors of offending behavior are generally similar for men and women, with the exception of IPV, where self-control was a better predictor of IPV for men and anger was a better predictor of IPV for women. Limitations of the present sample and suggestions for future work are discussed. Aggr. Behav. 9999:1-9, 2015. ๑) 2015 Wiley Periodicals, Inc.

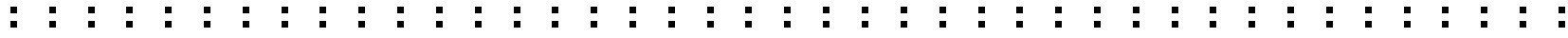

Keywords: partner violence; domestic violence; aggression; offending behavior; sex differences; abuse; anger; self-control; psychopathic traits

\section{INTRODUCTION}

In the general theory of crime (Gottfredson \& Hirschi, 1990), the tendency to commit any violent act, including intimate partner violence (IPV), is viewed as part of an overall propensity to commit criminal acts. Similarly, the general theory of violence (Felson, 2002) holds that IPV shares common features with other types of violent offending. Likewise, general theories of aggression (e.g., Anderson \& Bushman, 2002; Berkowitz, 1993; Finkel, 2007), view IPV as operating according to a set of principles that apply to all forms of aggressive behavior.

An alternative view is that criminally inclined individuals specialize in specific types of criminal behavior. Consistent with this overall approach (although developed separately from it), IPV has been regarded as a crime that is largely carried out by men who are not necessarily criminal in other respects. It, therefore, warrants separate study and a different theoretical approach, one that emphasizes the impact of patriarchal values (e.g., Dobash, Dobash, Wilson, \& Daly, 1992), or evolved responses to sexual jealousy (e.g., Daly \& Wilson, 2000). According to such specific explanations for IPV, we would not necessarily expect the same men to be violent outside their relationships or to commit other unrelated offences. These specific explanations do not address women's offending in any way.

Which of these views is correct will be informed by studies that investigate whether different broad categories of offending behavior are related to similar intrapersonal factors, and whether these are similar for men and women. There is some research showing an overlap between IPV and other forms of aggression (e.g., Archer \& Webb, 2006; Langhinrichsen-Rohling, Huss, \& Ramsey, 2000; Waltz, Babcock, Jacobson, \& Gottman, 2000). The current research broadens the scope of such investigations by studying both violent and nonviolent offending in both sexes in relation to

${ }^{*}$ Correspondence to: Abigail Thornton, School of Psychology, University of Central Lancashire, United Kingdom, PR1 2HE. E-mail: athornton4@uclan.ac.uk

Received 22 June 2013; Revised 15 October 2015; Accepted 30 October 2015

DOI: $10.1002 / a b .21635$

Published online XX Month Year in Wiley Online Library (wileyonlinelibrary.com). 
several intrapersonal variables that are likely to be associated with such offending. We selected variables that represent impelling and inhibiting factors in a general model of aggression, the $\mathrm{I}^{3}$ theory (Finkel, 2007). Specifically, we studied anger-proneness (strong impelling), self-control (weak inhibiting), and psychopathic traits (both weak inhibiting and strong impelling). We used a previously developed comprehensive measure of different types of criminal behavior (Thornton, GrahamKevan, \& Archer, 2013), to assess commonalities and differences across offense types and the two sexes.

\section{Sex Differences in Offending Behavior}

Nonviolent offending includes drug-related behavior, theft, and criminal damage. Men have been found to consistently engage in more of these offenses than women (e.g., Moffitt, Caspi, Rutter, \& Silva, 2001; Steffensmeier \& Allan, 1996). Likewise, men consistently show greater frequency and severity of violent offending than women at all ages and in all settings (e.g., Archer, 2004), except for IPV where the sex difference is not found in representative samples in western nations (e.g., Archer, 2000, 2006, 2013; Moffitt et al., 2001).

As a result of the generally higher male rates, research on violent and nonviolent offending behavior has commonly focused on men. From the research into violent offending, it has been inferred that women are different from men in their capacity and motivation for violence, and some researchers use the sex difference in violence outside the home as evidence that women are generally not violent and are only violent in relationships when they need to be, for example, in self-defense (e.g., Dobash et al., 1992). Therefore, examination of general violence (where there is a sex difference) and IPV (where there is not in western samples) in men and women may reveal similarities and differences between them and/or between the sexes.

\section{Variables Used in the Current Study}

Trait anger is a reliable predictor of violent crime (Howells, 1998) and is a risk factor that strengthens a person's violence-impelling forces (Finkel et al., 2012). Violent offenders have higher levels of anger-proneness than nonviolent offenders (e.g., Archer \& Haigh, 1997; Cornell, Peterson, \& Richards, 1999). Consistent with previous research, we expected to find that anger would be associated with violent offending (including IPV) but would be unrelated to nonviolent offending.

Typically, studies tend not to find sex differences in the experience or expression of anger in adults (Archer, 2004; Costa, Terracciano, \& McCrae, 2001; Driscoll, Zinkivskay, Evans, \& Campbell, 2006), although some have found a sex difference in the female direction (e.g., Brebner, 2003; Ramirez, Santisteban, Fujihara, \& Van
Goozen, 2002). However, men and women may differ in the ways that they express anger, with men being more likely to physically and verbally aggress against their target (e.g., Timmers, Fischer, \& Manstead, 1998), and women being more likely to cry (e.g., Vingerhoets, Cornelius, Van Heck, \& Becht, 2000) or talk to someone external to the situation (Simon \& Nath, 2004).

Other research has found that women are less likely than men to directly aggress against the target of their anger (Campbell, 2006), which was attributed to their greater self-control than men. Such a sex difference in anger expression may explain the sex difference in the perpetration of physical aggression (Campbell \& Muncer, 2008). The majority of research in the area of anger has focused on male perpetrators of violence; therefore, anger as a predictor of female violence needs further investigation, particularly in relation to anger among domestically violent women (Babcock, Canady, Graham, \& Schartm 2007).

Self-control is an important variable in relation to both crime and aggression. Gottfredson and Hirschi (1990) argued that all crime, violent, or otherwise, whether perpetrated by men or women, stems from the same underlying cause, a combination of low self-control and criminal opportunities. This was supported by a metaanalysis (Pratt \& Cullen, 2000), and subsequent empirical research (e.g., Blackwell \& Piquero, 2005; Tittle, Ward, \& Grasmick, 2003). In Finkel's I $I^{3}$ framework, individuals with low self-control are viewed as having weak violenceinhibiting forces (Finkel et al., 2012). They are, therefore, less able to control or restrain their emotions or behavior, and are more likely to express their anger in the form of overt aggression than are those with high self-control. They will, therefore, tend to act impulsively in response to provocation (Alexander, Allen, Brooks, Cole, \& Campbell, 2004; Driscoll et al., 2006).

Low self-control should also be associated with IPV and there is evidence that this is so (Archer, FernándezFuertes, \& Thanzami, 2010; Bates, Archer, \& GrahamKevan, 2015). However, the relation between selfcontrol and IPV has been queried (Moffitt, Kreuger, Caspi, \& Fagan, 2000), on the grounds that IPV is wilful and intentional rather than impulsive (e.g., Corvo \& Johnson, 2003, Appendix A). Felson and Massoglia (2012) found that for men IPV was less likely to be planned than were violent offenses involving strangers, whereas for women IPV was as likely to be planned as was violence toward strangers. This suggests that IPV may be more impulsive (and less planned) for men rather than women. Despite these complexities, it appears that, in general, individuals with low self-control are unlikely to specialize in any particular type of crime. Rather, they are likely to be versatile and commit any crime when there is the opportunity to do so. 
Psychopathic traits have been linked with criminal behavior, including severe and violent crimes (Hare, 1994, 1999; Hemphill, 2007; Leistico, Salekin, DeCoster, \& Rogers, 2008; Porter \& Woodworth, 2006; Walters, 2003). Psychopaths tend to be criminally versatile (e.g., Hart \& Hare, 1996), and, therefore, psychopathic traits may be useful for identifying similarities between different types of violent and nonviolent offenders.

Psychopathic traits have not been researched extensively in relation to IPV (Douglas, Vincent, \& Edens, 2006, but see Bates et al., 2015), although there is some evidence of deficits in affect, including empathy, remorselessness, and poor emotional expression (Dutton, 2003, 2006; Holtzworth-Munroe \& Stuart, 1994; Holtzworth-Munroe, Meehan, Herron, Rehman, \& Stuart, 2000; Swogger, Walsh, \& Kosson, 2007; Umberson, Anderson, Williams, \& Chen, 2003), among IPV perpetrators. Psychopathy is likely to be relevant to the study of IPV and other offending, as it may influence both impelling and inhibiting forces, principally weakening violence-inhibiting forces, but may also serve to strengthen violence-impelling forces (Finkel, 2007). In the three-category typology of IPV proposed by Holtzworth- Munroe and Stuart (1994), generally violent/ antisocial perpetrators were the most likely to show psychopathic traits. Consistent with this, Walsh et al. (2010) found that high levels of psychopathy occurred in generally violent/antisocial men and women. Therefore, psychopathic traits seem to be most related to offenders who offend generally, perpetrating violence in as well as outside their relationships, and also engaging in nonviolent offending behavior. Therefore, psychopathic traits may be important for linking IPV perpetrators with generally violent offenders. We, therefore, expected psychopathic traits to be associated with IPV, general violence and nonviolent offenses in the same sample.

Although the structure of psychopathy is still debatable (Cooke, Michie \& Hart, 2006; Neumann \& Hare, 2008), Hare (2003) suggested a minimum of two factors for adults. These are Factor 1, the interpersonal affective factor, characterized by traits such as manipulation, remorseless, callousness, and a lack of empathy; and Factor 2, the impulsive factor, characterized by traits such as poor behavioral control, risk taking, and irresponsibility. In the present study, we analyzed the subscales associated with these factors separately, as there is some evidence that they may have different associations with IPV and aggression outside the home for men and women (Bates et al., 2015).

\section{The Present Study}

The variables measured in this study were chosen using Finkel's $I^{3}$ framework, to investigate some of the likely impelling and inhibiting forces of offending behavior. Previous research has investigated each of these variables in relation to specific forms of offending but has not examined them together in a comparative context to inform the discussion on whether IPV is a different type of crime. Based on previous research it was predicted that (i) men will perpetrate more generally violent and nonviolent offenses than women, but women will perpetrate IPV at a similar frequency to men; (ii) there will be overlap between the three offense categories, demonstrated by significant correlations between IPV, general violence and nonviolent offending; there will also be overlap in the risk factors for offending across offense types and the sexes, such that (iii) anger will be associated with both IPV and general violence, but not with nonviolent offending; (iv) low self-control will be associated with all three types of offending; and (v) psychopathic traits will be associated with all three types of offending.

\section{METHOD}

\section{Participants}

Participants were a convenience sample recruited on a British university campus. There were 355 participants, 184 men and 171 women. Age ranged from 18 to 56 years with a mean of 21.75 (women $=21.82$, men $=21.68$ ). The response rate was $75.1 \%$. Of the 413 returned questionnaires, 58 were removed either due to missing data, or respondents not having had a partner in the past 12 months, or not being in a heterosexual relationship; therefore, 355 were retained for analysis. Individuals in homosexual relationships were not included in the present study because the number of responses was very low.

\section{Measures \\ Nonviolent and violent offending behavior scale (NVOBS: Thornton et al., 2013). The} NVOBS is a psychometrically sound measure of violent and nonviolent offending validated for use in a male and female student population (Thornton et al., 2013). The NVOBS is a 33-item scale, which measures IPV perpetration (eight items: e.g., kicked partner, hit partner with fist, slapped partner), general violence perpetration (12 items: e.g., kicked someone, hit someone with a fist, pushed grabbed, or shoved someone), and perpetration of nonviolent offenses (13 items: e.g., used cannabis, damaged something in a public place, stole £5-50). Participants were asked to report the extent to which they had perpetrated each act during the past 12 months. This time period is commonly used in both studies of IPV (e.g., in the CTS: Straus, 1979) and in general aggression research (e.g., Richardson \& Green, 1999, 2003). Items 
were answered on a 7-point scale from 0 (never happened) to 6 (happened more than 25 times). Scores were summed for each NVOBS subscale. For IPV, scores could range from 0 to a possible 48; however, the observed range (after dealing with outliers as stated in the results section) was $0-4$ for men, and $0-12$ for women. For general violence, scores could range from 0 to a possible 72 , however, the observed range was 0-27 for men, and 0-16 for women. For nonviolent offending, scores could range from 0 to a possible 78 ; however, the observed range was $0-16$ for men, and $0-6$ for women. Cronbach's alpha was $\alpha=.79$ for IPV, $\alpha=.89$ for general violence, and $\alpha=.71$ for nonviolent offending.

Anger subscale of Buss-Perry aggression questionnaire (BPAQ: Buss \& Perry, 1992). We used the anger subscale of the BPAQ, which consisted of seven questions, for example, "I flare up quickly but get over it quickly." Items were scored on a scale of 1-5 where $1=$ "extremely uncharacteristic of me" and $5=$ "extremely characteristic of me." Question 4 was reverse-scored. Scores could range from 7 to 35 . Reliability was $\alpha=.83$.

Brief self-control scale (BSCS: Tangney, Baumeister, \& Boone, 2004). The brief 13-item scale of the SCS was used, and included items such as "Sometimes I can't stop myself from doing something, even if I know it is wrong."; "I often act without thinking through all the alternatives." Participants were asked to read each statement and then report the extent to which it reflected how they typically behave, on a scale of 1-5 where $1=$ not at all and $5=$ very much. Items $2,3,4,5$, $10,14,15,17$, and 18 were reverse scored. Scores could range from 13 to 65. Tangney et al. (2004) found that the BSCS correlated with anger, personality pathology, and physical aggression. Reliability was $\alpha=.80$.

Youth psychopathic trait inventory (YPI: Andershed, Kerr, Stattin, \& Levander, 2002). The YPI is a 50-item questionnaire, designed for use in a non-referred or general population sample aged 12 and above, and was used to measure two factors of psychopathy. Factor 1 assesses interpersonal affective deficits, and Factor 2 assesses an impulsive and irresponsible lifestyle. Examples of Factor 1 items include "To get people to do what I want, I often find it efficient to con them"; "To feel guilty and remorseful about things you have done that have hurt other people is a sign of weakness"; "I don't let my feelings affect me as much as other people's feelings seem to affect them." Examples of Factor 2 items include "I like to do things just for the thrill of it"; "It often happens that I do things without thinking ahead." Questions were scored on a scale of 1-4 where $1=$ "does not apply at all" and $4=$ "applies very well." Recent research has used the
YPI in a university student sample (Peace \& Sinclair, 2012), showing that it is suitable for the present sample. Scores could range from 35 to 140 for Factor 1 psychopathic traits, and 15-60 for Factor 2 psychopathic traits. Reliability was $\alpha=.93$ for Factor 1 , and $\alpha=.83$ for Factor 2 .

Procedure. The questionnaire pack was distributed to university students on campus at a British university, along with return envelopes. Participants were recruited from open access computer rooms, the university library and from large lectures. They were from a variety of courses, including psychology. Students did not receive course credit or compensation for taking part in the research. They were told that the data would be anonymous and that they could withdraw at any time before handing in the questionnaire, but once they had returned it, this would not be possible. Participants were told about the purpose of the research on the front cover sheet of the questionnaire and were given the opportunity to ask any questions during debriefing following the completion of the questionnaire. The study conformed to BPS ethical guidelines and was given ethical approval from the departmental ethics committee.

\section{RESULTS}

Prior to analysis, the data were screened for accuracy, missing data, outliers, and normality (Tabachnick \& Fidell, 2007). Outliers were reduced so that extreme scores were one unit more than the next most extreme score.

\section{Sex Differences}

A one-way between subjects multivariate analyses of variance was used to test for sex differences in each offense category. There was a significant difference between men and women on the combined dependent variables $(F(3,350)=45.75, P<.001$, Wilks' Lambda $=.72$, partial eta squared $=.28$ ). Considering the dependent variables separately, we found support for prediction (1). Women reported perpetrating significantly more IPV than men, men were more violent than women outside relationships, and men perpetrated significantly more nonviolent offenses than women. All these effects were medium-sized according to criteria of Cohen (1988). Table I shows the means and standard deviations for each offense category, and $F$ and $d$ values for the sex differences.

A one-way between subjects multivariate analyses of variance was used to test for sex differences in each risk factor. There was a significant difference between men and women on the combined dependent variables $(F(4$, $310)=18.48, P<.001$, Wilks' Lambda $=.81$, partial eta squared $=.19$ ). . Considering the dependent variables 
TABLE I. Means and Standard Deviations for Offense Categories and Risk Factor Variables, for Men and Women $(N=184 \mathrm{Men}$, 171 Women), and $F$ and $d$ Values for Sex Differences

\begin{tabular}{|c|c|c|c|c|}
\hline & Men & Women & & \\
\hline Variables & $M(\mathrm{SD})$ & $M(\mathrm{SD})$ & $F(\mathrm{df})$ & $d^{\mathrm{a}}$ \\
\hline IPV - perpetration & $0.65(1.14)$ & $2.63(3.56)$ & $51.29(1,352)^{* *}$ & -0.75 \\
\hline General violence & $7.60(8.20)$ & $3.77(5.08)$ & $27.45(1,352)^{* *}$ & 0.56 \\
\hline Nonviolent offending & $3.71(4.80)$ & $1.42(2.11)$ & $32.78(1,352)^{* *}$ & 0.62 \\
\hline Anger & $16.71(5.52)$ & $17.68(6.00)$ & $2.21(1,313)$ & -0.17 \\
\hline Self-control & $37.81(8.22)$ & $39.19(7.04)$ & $2.54(1,313)$ & -0.18 \\
\hline Factor 1 psychopathy & $71.61(16.51)$ & $59.38(13.82)$ & $50.79(1,313)^{* *}$ & 0.80 \\
\hline Factor 2 psychopathy & $33.01(6.63)$ & $30.54(6.30)$ & $11.44(1,313)^{* *}$ & 0.38 \\
\hline
\end{tabular}

** $P<.01$.

${ }^{a}$ Minus sign signifies higher values for women than men.

separately, men and women did not differ on levels of anger or self-control. Men scored higher than women on Factor 1 and Factor 2 psychopathic traits, with medium to large effect sizes (Cohen, 1988). Table I shows the means and standard deviations for each risk factor, and $F$ and $d$ values for the sex differences.

\section{Correlational Analyses}

Table II shows the Pearson correlations between the offense categories and each risk factor variable, separately for the two sexes. There was no evidence of multicolinearity as there were no correlations above .7. There were some common associations across the three categories of offending. IPV, general violence, and nonviolent offending were significantly related in both sexes, demonstrating a degree of overlap between the different offense types, and providing support for prediction (2).

Sex differences in risk factors within each offense category were assessed by converting each correlation coefficient into a z-score using Fisher's r-to-z transformation, and then comparing these $z$-scores, using the formula from Cohen and Cohen (1983, p. 54). There were no significant sex differences, all values being less than 1.96 .

\section{Regression Analysis}

It is evident from Table $\mathrm{I}$ that the data are overdispersed (standard deviations are higher than the corresponding means). The preferred method of analysis for such data sets is negative binomial regression (Hilbe, 2007). This has been used in recent studies of IPV (e.g., Archer et al., 2010; Finkel, DeWall, Slotter, Oaten, \& Foshee, 2009; Thornton et al., 2013), and was used in the current study to assess the predictors of IPV, general violence, and nonviolent offending. Table III displays the results. The predictor variables were sex, anger, self-control, Factor 1 psychopathic traits, and Factor 2 psychopathic traits. Sex was also used in interaction with the other four psychological predictors.

IPV. The goodness of fit statistic was satisfactory as the Pearson $\chi^{2}$ value was near $1($ Value/df $=1.21)$. Anger significantly predicted IPV. Thus a higher endorsement of trait anger is associated with being physically aggressive toward a partner. There were also some significant interactions between sex and anger, and sex and self-control, such that men with lower self-control were more likely to aggress against their partners than women with lower self-control were, and women with

TABLE II. Pearsons Correlations Between IPV, General Violence (GV), Nonviolent Offending (NV), Anger, Self-Control, and Psychopathic Traits, for Men's and Women's Self-Reports $(N=184$ Men, 171 Women $)$

\begin{tabular}{|c|c|c|c|c|c|c|}
\hline & \multicolumn{3}{|c|}{ Men } & \multicolumn{3}{|c|}{ Women } \\
\hline & GV & IPV & $\mathrm{NV}$ & GV & IPV & $\mathrm{NV}$ \\
\hline GV & - & $.25^{* * *}$ & $.19^{* *}$ & - & $.41^{* * *}$ & $.31^{* * *}$ \\
\hline IPV & - & - & $.24^{* * *}$ & - & - & $.22^{* *}$ \\
\hline Anger & $.34^{* * *}$ & .10 & .03 & $.40^{* * *}$ & $.29^{* * *}$ & .12 \\
\hline Self-control & -.11 & $-.20^{* *}$ & $-.36^{* * *}$ & $-.22^{* *}$ & -.12 & $-.21^{* *}$ \\
\hline Factor 1 psychopathy & $.27^{* * *}$ & $.35^{* * *}$ & $.20^{* *}$ & $.38^{* * *}$ & $.27^{* * *}$ & $.32^{* * *}$ \\
\hline Factor 2 psychopathy & $.15^{*}$ & $.26^{* * *}$ & $.38^{* * *}$ & $.33^{* * *}$ & $.27^{* * *}$ & $.31^{* * *}$ \\
\hline
\end{tabular}

Note. For men $n$ 's ranged from 173 to 184 . For women $n$ 's ranged from 163 to 171 .

${ }^{* *} P<.01 .{ }^{* * *} P<.001$. 
TABLE III. Negative Binomial Regression for Anger, Self-Control, and Psychopathic Traits, as Predictors of (1) IPV, (2) General violence, and (3) Nonviolent Offending ( $N=184$ Men, 171 Women)

\begin{tabular}{|c|c|c|c|c|c|c|c|c|c|}
\hline \multirow[b]{2}{*}{ Parameter } & \multicolumn{3}{|c|}{ IPV } & \multicolumn{3}{|c|}{ General violence } & \multicolumn{3}{|c|}{ Nonviolent offending } \\
\hline & $B$ & SE & Wald $\chi^{2}$ & $B$ & SE & Wald $\chi^{2}$ & $B$ & SE & Wald $\chi^{2}$ \\
\hline Intercept & -3.38 & 1.30 & $6.72^{*}$ & -1.64 & 1.23 & 1.76 & -.05 & 1.28 & .00 \\
\hline Gender & 2.62 & 2.21 & 1.40 & 1.56 & 1.53 & 1.03 & -.24 & 1.70 & .02 \\
\hline Anger & .06 & .02 & $11.43^{* * *}$ & .07 & .02 & $10.25^{* * *}$ & -.03 & .02 & 1.92 \\
\hline Self-control & .04 & .02 & 2.60 & .01 & .02 & .07 & -.03 & .02 & 1.97 \\
\hline Factor 1 psychopathy & .01 & .01 & .65 & .02 & .01 & $5.66^{*}$ & .02 & .01 & $5.31^{*}$ \\
\hline Factor 2 psychopathy & .04 & .03 & 2.17 & .01 & .02 & .28 & .02 & .02 & .67 \\
\hline Gender* anger & -1.00 & .03 & $8.13^{* *}$ & .01 & .03 & .28 & -.00 & .03 & .00 \\
\hline Gender* self-control & -.08 & .03 & $7.02^{* *}$ & -.01 & .02 & .08 & -.00 & .03 & .02 \\
\hline Gender* factor 1 psychopathy & .03 & .01 & 3.54 & -.01 & .01 & .82 & -.02 & .01 & 1.64 \\
\hline Gender* factor 2 psychopathy & -.04 & .04 & .92 & -.01 & .03 & .11 & .06 & .03 & 3.31 \\
\hline
\end{tabular}

${ }^{*} P<.05 .{ }^{*} P<.01{ }^{* * *} P<.001$.

higher trait anger were more likely to aggress against their partner than men with higher trait anger were.

General violence. The goodness of fit statistic was again satisfactory (Value/df $=1.22$ ). Anger and Factor 1 psychopathy were significant positive predictors of general violence. Thus, men and women scoring higher on these traits are more likely to be physically aggressive toward someone other than their partner. There were no significant interactions between sex and the other psychological predictors, indicating that the associations were similar for men and women.

Nonviolent offending. The goodness of fit statistic was again satisfactory (Value/df $=1.38$ ). Factor 1 psychopathic traits was the only significant (positive) predictor of nonviolent offending. Again, there were no interactions between sex and the other psychological predictors.

In summary, from the results we found support for prediction (3) as anger was associated with both IPV and general violence, and not with nonviolent offending. We did not find support for prediction (4), as low self-control was only associated with IPV, and not with general violence or nonviolent offending. We also did not find support for prediction (5) as psychopathic traits were only associated with general violence and nonviolent offending, and not with IPV.

\section{DISCUSSION}

The sex differences in the three scales on the NVOBS were consistent with previous research. Men were more violent than women outside of the home (e.g., Archer, 2004, 2009; Moffitt et al., 2001), and they reported committing more nonviolent offenses than women (e.g., Moffitt et al., 2001; Steffensmeier \& Allan, 1996). Thus, on these measures, men are generally more antisocial than women. In contrast, women reported perpetrating more IPV than men did. This is again consistent with some of the previous research showing that women may report more physical aggression than men within intimate relationships in some samples and contexts, although a more typical finding is no difference (e.g., Archer, 2000; Bates et al., 2014; Moffitt et al., 2001; Thornton, Graham-Kevan, \& Archer, 2010). Archer (2006) found that this sex difference in IPV varied crossnationally with the degree of gender equality, so that this pattern is only characteristic of developed western nations, such as the UK, USA, and Canada, where gender equality and individualism are both high. We should also note that sex differences are slightly more in the female direction for perpetrators' than for victims' reports (Archer, 2000), owing to slightly more divergence between perpetrators' and victims' reports for men than for women (Archer, 1999).

The results indicate moderate correlations between the three offense types for men and women, which suggests that men and women tend to be generalist offenders. This finding supports previous research, which has found that offenders tend to be versatile and perpetrate a variety of criminal acts (e.g., Farrington et al., 2006; Gottfredson \& Hirschi, 2007). The findings also support previous research showing that men and women who are violent within their relationships also tend to be violent toward others outside of their relationship (e.g., Moffitt et al., 2000; Thornton et al., 2010).

Overall, the associations between the risk factor variables used in this study were similar for the three categories of offense and for the two sexes. Anger was significantly associated with general violence, and this did not differ for men and women, suggesting that both sexes share anger as a common risk factor for general violent offending. This finding is consistent with the general association between anger and aggression (e.g., Berkowitz, 1989, 2008). Previous studies have found a link between anger and low agreeableness (e.g., Caprara, 
Barbaranelli, \& Zimbardo, 1996; Thornton et al., 2010), and both of these have been associated with aggression in response to provocation (Bettencourt \& Miller, 1996). Therefore, if women are provoked they may be just as likely as men to express their anger as aggression. The current research did not assess the conditions under which aggression was perpetrated (e.g., provocation or neutral conditions), but this would be useful to consider in future research.

Previous research has found an association between anger-proneness and the perpetration of violent offenses (Howells, 1998), and that it reliably distinguishes between violent and nonviolent offenders (Cornell et al., 1999). Consistent with this, we also found that anger was associated with violent but not nonviolent crime.

In contrast to the similar predictors for men and women for general violence and nonviolent offending, there were some sex differences in the predictors of IPV. Low self-control better predicted men's than women's IPV, whereas anger better predicted women's than men's IPV. The latter finding is inconsistent with the self-defensive theory of women's IPV (e.g., Dobash et al., 1992), since this would predict that fear rather than anger should be associated with women's perpetration of IPV. The link between low self-control and men's IPV suggests that men's violence may be more impulsive, and less planned, than women's. This finding is consistent with that of Felson and Massoglia (2012) that men's violence toward their female partners is less likely to be planned. Using Finkel's (2007) framework, it appears that weak violence-inhibiting forces may be a better predictor of men's IPV, and strong violenceimpelling forces a better predictor of women's IPV.

Although there were some significant Pearson correlations between psychopathic traits and all three offense types for both sexes, these were generally not significant predictors in the regression, that is, they acted via other variables. In the regression analyses, it was only Factor 1 psychopathic traits that were significantly associated, and only with general violence and nonviolent offending. Individuals with these traits take advantage of and violate the rights of others and have an inflated sense of entitlement and self-importance.

The limitations of this research concern the sample used and the cross-sectional design. The sample was derived from a University student population, and may, therefore, not be representative of the UK population, as those from a university sample are generally at a lower risk of offending, or their crimes are likely to be relatively minor. However, a number of studies indicate that undergraduate students do self-report acts of IPV and other forms of aggression that would be classed as criminal offenses (e.g., Archer, 2002; Bates, GrahamKevan, \& Archer, 2014; Barratt, Stanford, Dowdy,
Liebman, \& Kent, 1999; Cross \& Campbell, 2012; Fiebert \& Gonzalez, 1997; Smith \& Waterman, 2006; Straus \& Ramirez, 2004; Straus, 2008; Thornton et al., 2010, 2013). Therefore, using a student population does enable us to examine the overlap between self-reported offending in a sample unselected for criminal behavior. Therefore, student samples may show similar patterns of offending to non-student samples, but at lower rates. Nevertheless, the findings from this study deserve replication in the wider community and in at-risk samples. A second limitation is that the study used a cross-sectional design, investigating the relationships between offending and associated risk factors at a specific point in time. Future research would benefit from a longitudinal design.

Overall, the results suggest that offending behavior is related to similar intra-personal factors for men and women, with the exception of IPV. Anger predicted women's general violence and IPV, which supports Felson's (2002) theory that violence has similar causal influences irrespective of whether the target is an intimate partner or someone else. However, there were also different predictors of men's and women's IPV perpetration; low self-control better predicted men's IPV, whereas anger better predicted women's IPV. This provides some support for the view that men's IPV has different causes from women's, and possibly the function of the violence is different for the two sexes.

\section{REFERENCES}

Alexander, F., Allen, C., Brooks, J., Cole, C., \& Campbell, A. (2004). Reason to believe: Representations of aggression as phenomenological read-out. Sex Roles, 51, 647-659. doi: 10.1007/s11199-004-0716-z

Andershed, H., Kerr, M., Stattin, H., \& Levander, S. (2002). Psychopathic traits in non-referred youths: A new assessment tool. In Blauw E. \& Sheridan L. (Eds.), Psychopaths: Current international perspectives. (pp. 131-158). The Hague: Elsevier.

Anderson, C. A., \& Bushman, B. J. (2002). Human aggression. Annual Review of Psychology, 53, 27-51. doi: 10.1146/annurev.psych.53. 100901.135231

Archer, J. (1999). Assessment of the reliability of the conflict tactics scales: A meta-analytic review. Journal of Interpersonal Violence, 14 1263-1289. doi: 10.1177/088626099014012003

Archer, J. (2000). Sex differences in aggression between heterosexual partners: A meta-analytic review. Psychological Bulletin, 126, 651-680. doi: 10.1037/0033-2909.126.5.651

Archer, J. (2002). Sex differences in physically aggressive acts between heterosexual partners: A meta-analytic review. Aggression and Violent Behavior: A Review Journal, 7, 313-351. doi: 10.1016/S1359-1789 (01)00061-1

Archer, J. (2004). Sex difference in aggression in real-world settings: A meta- analytic review. Review of General Psychology, 8, 291- 322. doi: 10.1037/1089-2680.8.4.291

Archer, J. (2006). Cross-cultural differences in physical aggression between partners: A social-role analysis. Personality and Social Psychology Review, 10,133-153. doi: 10.1207/s15327957pspr1002_3 
Archer, J. (2009). Does sexual selection explain human sex differences in aggression? Behavioral and Brain Sciences, 32, 249-311. doi: 10.1017/S0140525X09990951

Archer, J. (2013). Can evolutionary principles explain patterns of family violence? Psychological Bulletin, 138, 403-440. doi: 10.1037/ a0029114

Archer, J., Fernández-Fuertes, A. A., \& Thanzami, V. L. (2010). Does cost-benefit analysis or self-control predict involvement in two forms of aggression? Aggressive Behavior, 36, 292-304. doi: 10.1002/ ab. 20358

Archer, J., \& Haigh, A. (1997). Do beliefs about aggressive feelings and actions predict reported levels of aggression? British Journal of Social Psychology, 36, 83-105. doi: 10.1111/j. 2044-8309.1997.tb01120.x

Archer, J., \& Webb, I. A. (2006). The relation between scores on the BussPerry aggression questionnaire and aggressive acts, impulsiveness, competitiveness, dominance and sexual jealousy. Aggressive Behavior, 32, 464-473. doi: 10.1002/ab.20146

Babcock, J. C., Canady, B. E., Graham, K., \& Schart, L. (2007). The evolution of battering interventions: From the dark ages into the scientific age. In Hamel J. \& Nicholls T. L. (Eds.), Family interventions in domestic violence: A handbook of gender-inclusive theory and treatment. (pp. 215-244). New York: Springer.

Barratt, E. S., Stanford, M. S., Dowdy, L., Liebman, M. J., \& Kent, T. A. (1999). Impulsive and premeditated aggression: A factor analysis of self-reported acts. Psychiatry Research, 86, 163-173. doi: 10.1016/ S0165-1781(99)00024-4

Bates, E. A., Archer, J., \& Graham-Kevan, N. (2015). Impelling and inhibiting influences on aggression towards partners and same-sex others. Unpublished manuscript.

Bates, E. A., Graham-Kevan, N., \& Archer, J. (2014). Testing predictions from the male control theory of men's partner violence. Aggressive Behavior, 40, 42-55. doi: 10.1002/ab.21499

Berkowitz, L. (1989). Frustration-aggression hypothesis: Examination and reformulation. Psychological Bulletin, 106, 59-73. doi: 10.1037/ 0033-2909.106.1.59

Berkowitz, L. (1993). Aggression: Its causes, consequences, and control. New York: McGraw-Hill.

Berkowitz, L. (2008). On the consideration of automatic as well as controlled psychological processes in aggression. Aggressive Behavior, 34, 117-129. doi: 10.1002/ab.20244

Bettencourt, B. A., \& Miller, N. (1996). Gender differences in aggression as a function of provocation: A meta-analysis. Psychological Bulletin, 119, 422-447. doi: 10.1037/0033-2909.119.3.422

Blackwell, B. S., \& Piquero, A. R. (2005). On the relationships between gender, power control, self-control, and crime. Journal of Criminal Justice, 33, 1-17. doi: 10.1016/j.jcrimjus.2004.10.001

Brebner, J. (2003). Gender and emotions. Personality and Individual Differences, 34, 387-394. doi: 10.1016/S0191-8869(02)00059-4

Buss, A. H., \& Perry, M. (1992). The aggression questionnaire. Journal of Personality and Social Psychology, 63, 452-459. doi: 10.1037/00223514.63.3.452

Campbell, A. (2006). Sex differences in direct aggression: What are the psychological mediators? Aggression and Violent Behavior, 11, 237-264. doi: 10.1016/j.avb.2005.09.002

Campbell, A., \& Muncer, S. (2008). Intent to harm or injure? Gender and the expression of anger. Aggressive Behavior, 34, 282-293. doi: 10.1002/ab.20228

Caprara, G. V., Barbaranelli, C., \& Zimbardo, P. G. (1996). Understanding the complexity of human aggression: Affective, cognitive, and social dimensions of individual differences in propensity toward aggression. European Journal of Personality, 10, 133-155. doi: 10.1002/(SICI) 1099-0984(199606)10:2\%3C133::AID-PER252\%3E3.0.CO;2-E

Cohen, J. (1988). Statistical power analysis for the behavioral sciences (2nd ed.). Hillside, NJ: Lawrence Earlbaum Associates.
Cohen, J., \& Cohen, P. (1983). Applied multiple regression/correlation analysis for the behavioral sciences. Hillsdale, $\mathrm{NJ}$ : Erlbaum.

Cooke, D. J., Michie, C., \& Hart, S. (2006). Facets of clinical psychopathy: Toward clearer measurement. In Patrick C. J. (Ed.), The handbook of psychopathy. (pp. 91-106). New York: Guilford Press.

Cornell, D. G., Peterson, C. S., \& Richards, H. (1999). Anger as a predictor of aggression among incarcerated adolescents. Journal of Consulting and Clinical Psychology, 67, 108-115. doi: 10.1037/0022- 006X.67. 1.108

Corvo, K., \& Johnson, P. J. (2003). Vilification of the "batterer": How blame shapes domestic violence policy and interventions. Aggression and Violent Behavior, 8, 259-281. doi: 10.1016/S1359-1789(01) 00060-X

Costa, P. T., Terracciano, A., \& McCrae, R. R. (2001). Gender differences in personality traits across cultures: Robust and surprising findings. Journal of Personality and Social Psychology, 81, 322-331. doi: 10.1037/0022- 3514.81.2.322

Cross, C. P., \& Campbell, A. (2012). The effect of intimacy and target sex on direct aggression: Further evidence. Aggressive Behavior, 38, 272-280. doi: 10.1002/ab.21430

Daly, M., \& Wilson, M. I. (2000). Family violence: An evolutionary psychological perspective. Virginia Journal of Social Policy and the Law, 8, 77-121.

Dobash, R. P., Dobash, R. E., Wilson, M., \& Daly, M. (1992). The myth of sexual symmetry in marital violence. Social Problems, 39, 71-85. doi: $10.2307 / 3096914$

Douglas, K. S., Vincent, G. M., \& Edens, J. F. (2006). Risk for criminal recidivism: The role of psychopathy. In Patrick C. J. (Ed.), Handbook of psychopathy. (pp. 533-554). New York: Guildford.

Driscoll, H., Zinkivskay, A., Evans, K., \& Campbell, A. (2006). Gender differences in social representations of aggression: The phenomenological experience of differences in inhibitory control? British Journal of Psychology, 97, 139-153. doi: 10.1348/000712605X63073

Dutton, D. G. (2003). The abusive personality: Violence and control in abusive relationships (2nd ed.). New York: Guildford.

Dutton, D. G. (2006). Rethinking domestic violence. Canada: UBC Press.

Farrington, D. P., Coid, J. W., Harnett, L., Jolliffe, D., Soteriou, N., Turner, R., \& West, D. J. (2006). Criminal careers and life success: new findings from the Cambridge study in delinquent behaviour. Home Office Research study No. 281. London: Home Office.

Felson, R. B. (2002). Violence and gender re-examined. Washington, DC: American Psychological Association.

Felson, R. B., \& Massoglia, M. (2012). When is violence planned? Journal of Interpersonal Violence, 27, 753-774. doi: 10.1177/0886260511423238

Fiebert, M. S., \& Gonzalez, D. M. (1997). College women who initiate assaults on their male partners and the reasons offered for such behavior. Psychological Reports, 80, 583-590. doi: 10.2466/ pr0.1997.80.2.583

Finkel, E. J. (2007). Impelling and inhibiting forces in the perpetration of intimate partner violence. Review of General Psychology, 11, 193. doi: 10.1037/1089-2680.11.2.193

Finkel, E. J., DeWall, C. N., Slotter, E. B., Oaten, M., \& Foshee, V. A. (2009). Self-regulatory failure and intimate partner violence perpetration. Journal of Personality and Social Psychology, 97, 483-499. doi: 10.1037/a0015433

Finkel, E. J., DeWall, C. N., Slotter, E. B., McNulty, J. K., Pond, R. S. Jr, \& Atkins, D. C. (2012). Using $\mathrm{I}^{3}$ theory to clarify when dispositional aggressiveness predicts intimate partner violence perpetration. Journal of personality and social psychology, 102, 533. doi: 10.1037/a0025651

Gottfredson, M. R., \& Hirschi, T. (1990). A general theory of crime. USA: Stanford University Press.

Gottfredson, M. R., \& Hirschi, T. (2007). A general theory of crime, (3rd ed.). USA: Stanford University Press. 
Hare, R. D. (1994). Without conscience: The disturbing world of psychopaths among us. New York: Simon \& Schuster.

Hare, R. D. (1999). Psychopathy as a risk factor for violence. Psychiatric Quarterly, 70, 181-197. doi: 10.1023/A:1022094925150

Hare, R. D. (2003). Manual for the Hare psychopathy checklist. Revised 2nd ed. Toronto, ON: Multi-Health Systems.

Hart, S. D., \& Hare, R. D. (1996). Psychopathy and antisocial personality disorder. Current Opinion in Psychiatry, 9, 129-132. doi: 10.1097/ 00001504-199603000- 00007

Hemphill, J. F. (2007). The hare psychopathy checklist and recidivism: Methodological issues and critically evaluating empirical evidence. In Herve H., \& Yuille J. C. (Eds.), The psychopath: Theory, research, and practice. (pp. 141-170). Mahwah, NJ: Lawrence Erlbaum Associates.

Hilbe, J. M. (2007). Negative binomial regression. New York: Cambridge University Press.

Holtzworth-Munroe, A., Meehan, C., Herron, K., Rehman, U., \& Stuart, G. L. (2000). Testing the Holtzworth-Munroe and Stuart (1994) batterer typology. Journal of Consulting and Clinical Psychology, 68, 1000-1019. doi: 10.1037/0022-006X.68.6.1000

Holtzworth-Munroe, A., \& Stuart, G. L. (1994). Typologies of male batterers: Three subtypes and the differences among them. Psychological Bulletin, 116, 476-497. doi: 10.1037/0033-2909.116.3.476

Howells, K. (1998). Cognitive-behavioural interventions for anger, aggression and violence. In Tarrier N., Wells A., \& Haddock G. (Eds.), Personality, personality disorder, and risk of violence. (pp. 295-318). Chichester: Wiley.

Langhinrichsen- Rohling, J., Huss, M. T., \& Ramsey, S. (2000). The clinical utility of batterer typologies. Journal of Family Violence, 15, 37-53. doi: 10.1023/A:1007597319826

Leistico, A. M. R., Salekin, R. T., DeCoster, J., \& Rogers, R. (2008). A large-scale meta-analysis relating the Hare measures of psychopathy to antisocial conduct. Law and Human Behavior, 32, 28-45. doi: 10.1007/s10979-007-9096-6

Moffitt, T. E., Caspi, A., Rutter, M., \& Silva, P. A. (2001). Sex differences in antisocial behaviour. Conduct disorder, delinquency, and violence in the Dunedin longitudinal study. UK: Cambridge University Press.

Moffitt, T. E., Kreuger, R. F., Caspi, A., \& Fagan, J. (2000). Partner abuse and general crime: How are they the same, how are they different? Criminology, 38, 199-232. doi: 10.1111/j.1745-9125.2000.tb00888.x

Neumann, C. S., \& Hare, R. D. (2008). Psychopathic traits in a large community sample: Links to violence, alcohol use, and intelligence. Journal of Consulting and Clinical Psychology, 76, 893-899. doi: 10.1037/0022-006X.76.5.893

Peace, K. A., \& Sinclair, S. M. (2012). Cold-blooded lie catchers? An investigation of psychopathy, emotional processing, and deception detection. Legal and Criminological Psychology, 17, 177-191. doi: $10.1348 / 135532510 X 524789$

Porter, S., \& Woodworth, M. (2006). Psychopathy and aggression. In Patrick C. J. (Ed.), Handbook of psychopathy. (pp. 481-494). New York: Guilford Press.

Pratt, T. C., \& Cullen, F. T. (2000). The empirical status of Gottfredson and Hirschi's general theory of crime: A meta-analysis. Criminology, 38, 931-964. doi: 10.1111/j.1745-9125.2000.tb00911.x

Ramirez, J. M., Santisteban, C., Fujihara, T., \& Van Goozen, S. (2002). Differences between experience of anger and readiness to angry action: A study of Japanese and Spanish students. Aggressive Behavior, 28, 429-438. doi: 10.1002/ab.80014

Richardson, D. R., \& Green, L. R. (1999). Social sanction and threat explanations of gender effects on direct and indirect aggression. Aggressive Behavior, 25, 425-434. doi: 10.1002/(SICI)1098-2337 (1999)25:6<425::AID-AB3>3.0.CO;2-W

Richardson, D. R., \& Green, L. R. (2003). Defining direct and indirect aggression: The Richardson conflict response questionnaire. International Review of Social Psychology, 16, 11-30.
Simon, R. W., \& Nath, L. E. (2004). Gender and emotion in the United States: Do men and women differ in self-reports of feelings and expressive behaviour? American Journal of Sociology, 109, 1137-1176. doi: 10.1086/382111

Smith, P., \& Waterman, M. (2006). Self-reported aggression and impulsivity in forensic and nonforensic populations: The role of gender and experience. Journal of Family Violence, 21, 425- 437. doi: 10.1007/s10896-006-9039-x

Steffensmeier, D., \& Allan, E. (1996). Gender and crime: Toward a gendered theory of female offending. Annual Review of Sociology, 22, 459-487. doi: 10.1146/annurev.soc.22.1.459

Straus, M. A. (1979). Measuring intrafamily conflict and violence: The conflict tactics (CT) scales. Journal of Marriage and the Family, 41, 75-88. doi: $10.2307 / 351733$

Straus, M. A. (2008). Dominance and symmetry in partner violence by male and female university students in 32 nations. Children and Youth Services Review, 30, 252-275. doi: 10.1016/j.childyouth.2007.10.004

Straus, M. A., \& Ramirez, I. L. (2004). Criminal history and assault of dating partners: The role of type of prior crime, age of onset, and gender. Violence and Victims, 19, 413-434. doi: 10.1891/ vivi.19.4.413.64164

Swogger, M. T., Walsh, Z., \& Kosson, D. S. (2007). Domestic violence and psychopathic traits: Distinguishing the antisocial batterer from other antisocial offenders. Aggressive Behavior, 33, 253-260. doi: 10.1002/ab.20185

Tabachnick, B. G., \& Fidell, L. S. (2007). Using multivariate statistics (5th ed.). USA: Pearson Education.

Tangney, J. P., Baumeister, R. F., \& Boone, A. L. (2004). High selfcontrol predicts good adjustment, less pathology, better grades, and interpersonal success. Journal of Personality, 72, 271-322. doi: 10.1111/j.0022- 3506.2004.00263.x

Thornton, A. J. V., Graham-Kevan, N., \& Archer, J. (2010). Adaptive and maladaptive personality traits as predictors of violent and nonviolent offending behavior in men and women. Aggressive Behavior, 36, 177-186. doi: 10.1002/ab.20340

Thornton, A. J. V., Graham-Kevan, N., \& Archer, J. (2013). Development and confirmatory factor analysis of the nonviolent and violent offending behaviour scale (NVOBS). Aggressive Behavior, 39, 171-181. doi: 10.1002/ab.21468

Timmers, M., Fischer, A. H., \& Manstead, A. S. R. (1998). Gender differences in motives for regulating emotions. Personality and Social Psychology Bulletin, 24, 974-986. doi: 10.1177/ 0146167298249005

Tittle, C. R., Ward, D. A., \& Grasmick, H. G. (2003). Gender, age and crime/deviance: A challenge to self-control theory. Journal of Research in Crime and Delinquency, 40, 426-453. doi: 10.1177/ 0022427803256074

Umberson, D., Anderson, K. L., Williams, K., \& Chen, M. D. (2003). Relationship dynamics, emotion state, and domestic violence: A stress and masculinities perspective. Journal of Marriage and the Family, 65, 233-247. doi: 10.1111/j.1741-3737.2003.00233.x

Vingerhoets, A. J. J. M., Cornelius, R. R., Van Heck, G. L., \& Becht, M. C. (2000). Adult crying: A model and review of the literature. Review of General Psychology, 4, 354-377. doi: 10.1037/1089-2680.4.4.354

Walsh, Z., Swogger, M. T., O'Connor, B. P., Chatav Schonbrun, Y., Shea, M. T., \& Stuart, G. L. (2010). Subtypes of partner violence perpetrators among male and female psychiatric patients. Journal of Abnormal Psychology, 119, 563-574. doi: 10.1037/a0019858

Walters, G. D. (2003). Predicting institutional adjustment and recidivism with the psychopathy checklist factor scores: A meta-analysis. Law and Human Behavior, 27, 541-558. doi: 10.1023/A:1025490207678

Waltz, J., Babcock, J. C., Jacobson, N. S., \& Gottman, J. (2000). Testing a typology of batterers. Journal of Consulting and Clinical Psychology, 68, 658-669. doi: 10.1037/0022-006X.68.4.658 